\title{
Control of the American Cockroach (Periplaneta americana L.) and German Cockroach (Blattella germanica L.) in Canteens with Hydramethylnon Gel Bait
}

\author{
${ }^{1}$ Prachumporn Lauprasert, ${ }^{1}$ Jindawan Wibuluthai and ${ }^{2}$ Komsorn Lauprasert \\ ${ }^{1}$ Faculty of Public Health, ${ }^{2}$ Department of Biology, \\ Faculty of Science, Mahasarakham University, 44150 Mahasarakham, Thailand
}

\begin{abstract}
Hydramethylnon gel bait (Infinity ${ }^{\circledR}$ ) $2 \% \mathrm{w} / \mathrm{w}$ was evaluated as an insecticide agent against American cockroach (Periplaneta americana L.) and German cockroach (Blattella germanica L.) in 3 university canteens, Mahasarakham University, Thailand. The bait was reduced $>99 \%$ of cockroach trap counts in all sites after 1 week post-treatment with the only single treatment. Then, the reduction rate of all test sites was further sustained up to 4 weeks in the post-treatment. The American cockroach trap count was reduced significantly at the 1st week of the post-treatment to the 4 th week of the post-treatment $(>99 \%)$. Nevertheless, the reduction of $>70 \%$ was sustained from 5 weeks up to 10 weeks for the post-treatment. A minimum reduction of $52.38 \%$ shown at the twelfth week of the post-treatment. For the German cockroach trap count was reduced significantly gradually over $99 \%$ also at the first week to the 6 th week of the post-treatment. However, a reduction of over $70 \%$ was sustained from 7 weeks up to 12 weeks in the post-treatment. A minimum reduction of $61.90 \%$ shown at the 12th week of the post-treatment.
\end{abstract}

Key words: Hydramethylnon, gel bait, Periplaneta americana, Blattella germanica, cockroaches, Mahasarakham, Thailand

\section{INTRODUCTION}

The cockroaches are worldwide important urban pests in human environments (James and Harwood, 1969; Roth, 1991). Although, the cockroaches do not sting or bite but it can affect human health in several ways such as transmitting pathogenic agents mechanically from its body part (Brenner, 1995; Lee, 1997). The American and German cockroaches were reported as carriers of viruses, bacteria, fungi, protozoan and helminthes (Kang and Chang, 1985; Brenner et al., 1991; Ross and Mullins, 1995; Benson and Zungoli, 1997; Lee, 1997). The decomposing remains of dead cockroaches and their faeces are an important source of an air-borne disease by inducing respiratory allergies in sensitive people (Kang and Chang, 1985; Brenner et al., 1991; Ross and Mullins, 1995; Lee, 1997; Sarinho et al., 2004).

In Thailand, many cockroaches found are outdoor, indoor and also peridomestic species. At least 11 species of the cockroaches have been reported but only some species have medical significance (Tawatsin et al., 2001; Lauprasert, 2006). For example, the German cockroach, Blattella germanica Linnaeus, a small indoor pest which infests in the humid and warm environment such as commercial food preparation, storage facilities, kitchens, larders and restaurants (James and Harwood, 1969; Ross and Mullins, 1995). Another example is the American cockroach, Periplaneta americana Linnaeus which regularly inhabits in sewers, steam tunnels and drainage system (James and Harwood, 1969). Both of them are worldwide urban pests and are very difficult to control (Gold, 1995; Tsai and Lee, 2001).

In Southeast Asia, the German cockroach is an important insect pest in hotels and food preparative outlets (Lee et al., 1993; Lee, 1998). The current control strategies are reliable heavily on the use of neurotoxic insecticides in residual formulations in this region and have been found to be ineffective against multi-resistant German cockroaches (Lee et al., 1996, 2000; Lee and Lee, 2004).

Baits have become a popular and effective method in controlling the number of cockroaches (Agrawal and Tilak, 2006) especially against the German cockroach in Thailand (Sitthicharoenchai et al., 2006) and against the American cockroach in Malaysia (Sulaiman et al., 2007). The use of baits can also reduce the likelihood of pesticide misapplication (Robinson, 1988) and managed insecticide-resistant German cockroaches (Lee, 1998; Lee et al., 1996). Therefore, this study was carried on in the evaluation of hydramethylnon-based gel bait formula

Corresponding Author: Prachumporn Lauprasert, Faculty of Public Health, Mahasarakham University, 44150 Mahasarakham, Thailand 
in controlling the number of the American and German cockroaches in 3 university canteens in Mahasarakham University, Thailand.

\section{MATERIALS AND METHODS}

About 3 sites were used in this field evaluation at Mahasarakham University, Mahasarakham Province, Thailand, namely as the Plaza (the 2nd floor; approximately $200 \mathrm{~m}^{2}$ ): site $\mathrm{A}$, the central canteen (approximately $300 \mathrm{~m}^{2}$ ): site B and the Academic service canteen (D-building) (approximately $300 \mathrm{~m}^{2}$ ): site C. Site A is a moderate size canteen and consisted of a dinning area, food selling counters, food preparations and a central dish washing area. The site $\mathrm{B}$ is a large size canteen with large dining area and 13 stores selling different kinds of foods. Each store has its own foodselling counter, food preparation area and a central dish washing area. The site $\mathrm{C}$ is a large size canteen also with seven stores selling different kinds of foods. Each store has its own food-selling counter, food preparation area and dish washing area. From the pre-survey, all sites have moderate level infestation of American and German cockroaches. The bait gel were used in this study. The bait of hydramethylnon (Infinity ${ }^{\circledR}$, Welltech Healthcare Pte Ltd, Thailand) contains $2.0 \% \mathrm{w} / \mathrm{w}$ hydramethylnon and $98 \% \mathrm{w} / \mathrm{w}$ inert ingredients.

Prior to the treatment, the modified jar traps were used for the study. A modified jar trap was a plastic cup ( $8 \mathrm{~cm}$ in diameter and $11 \mathrm{~cm}$ in height) with the sticky crepe study fixed around the cup for cockroaches be able to enter. The upper 25th of the inner surface of the jar trap was coated with a thin film of petroleum jelly (Vaseline ${ }^{\circledR}$ ), the cockroaches once enter to the trap lured by food and then they would be unable to climb out. Following the technique reported by Wileyto and Boush (1983), the dog food saturated with beer was used as baits in this study (Lauprasert, 2006). The traps filled with bait were placed next to the walls and near the equipments in each shop and dish washing area for $24 \mathrm{~h}$. Each modified jar trap was covered by a wide steel mesh to prevent the disturbances by rats and other vertebrate pests. About 20 traps were placed in each site of this study. The traps were collected and taken to the laboratory where the cockroaches were identified and counted. The number and stage of of American and German cockroaches were recorded.

The nymphal stages were divided into 3 class sizes such as small nymphs were the 1st and 2nd instars, medium nymphs were the 3rd and 4th instars and large nymphs were the 5 th and 6 th instars. And the caught number was served as the basis for the comparison of post-treatment count. Treatments were made by applying the gel bait at the rate approximately $1.0 \mathrm{~g}$ per $\mathrm{m}^{2}$. Baiting was carried out on May 1, 2009 for site A canteen, May 2, 2009 for site B canteen and May 3, 2009 for the site C. Maximum number of placement of gel baits was made by treating as many spots as possible with more droplets or more bait being applied in heavily infested locations. For site A canteen, a total of 12 tubes were used while 25 tubes were applied in the site $\mathrm{B}$ canteen and 20 tubes were applied in site $\mathrm{C}$ canteen. Each tube consisted of $35 \mathrm{~g}$ of gel bait. This study was evaluated during 12 weeks after treatment. The post-treatment samplings were made at selected week intervals by means of the same procedure as reported in the pre-treatment. The Percentage Reduction (PR) in cockroach trap count was calculated by using the formula: $\mathrm{PR}=100((\mathrm{TO}-\mathrm{Ti}) / \mathrm{TO})$ where $\mathrm{T} 0$ is the number of cockroaches trapped at pre-treatment and $\mathrm{T} i$ is the number of cockroaches trapped at ith week in the post-treatment (Sitthicharoenchai et al., 2006).

\section{RESULTS AND DISCUSSION}

From this examination, the cockroaches were attracted to feed on the gel bait immediately after treated. The results showed that the hydramethylnon gel bait had high performance against American and German cockroaches in all sites test.

The American cockroach trap counts were reduced $>99 \%$ within one week after the post-baiting (Table 1 and Fig. 1) and the reduction was further progressed by the 2nd week of the post-treatment. Due to the effects of the gel bait on age-class distribution, it was found that the formulation affected on both adult and the nymphal stages in all sites.

Moreover, the German cockroach trap counts were also reduced over $99 \%$ within one week post-baiting (Table 2 and Fig. 2) and the reduction was further progressed by the second week post-treatment. On the effects of the gel bait on age-class distribution, it was found that the formulation also affected both adult and the nymphal stages in all sites.

The American cockroach traps count were initially reduced significantly at the first week of the posttreatment to the 4th week of the post-treatment (>99\%). Nevertheless, a reduction of over $70 \%$ was sustained from 5 weeks continuously up to 10 weeks of the posttreatment. A minimum reduction of $52.38 \%$ was showed at the 12 th week of the post-treatment in site C. For the German cockroach, cockroach trap count was initially reduced significantly also at the first week of the posttreatment to the 6 th week of the post-treatment (over $99 \%$ ). However, a reduction of over $70 \%$ was sustained from 7-12 weeks of the post-treatment in site C. 
Res. J. Biol. Sci., 5 (4): 318-322, 2010

\begin{tabular}{|c|c|c|c|c|c|c|c|c|c|}
\hline \multirow[b]{2}{*}{$\begin{array}{l}\text { Week (s) } \\
\text { after treatment }\end{array}$} & \multicolumn{3}{|l|}{ Site A } & \multicolumn{3}{|l|}{ Site B } & \multicolumn{3}{|l|}{ Site C } \\
\hline & Adult & Nymph & Total & Adult & Nymph & Total & Adult & Nymph & Total \\
\hline 0 (pre) & 22 & 6 & 28 & 45 & 6 & 51 & 16 & 6 & 21 \\
\hline 1 & 0 & 0 & 0 & 0 & 0 & 0 & 0 & 0 & 0 \\
\hline 2 & 0 & 0 & 0 & 0 & 0 & 0 & 0 & 0 & 0 \\
\hline 3 & 0 & 0 & 0 & 0 & 0 & 0 & 0 & 0 & 0 \\
\hline 4 & 0 & 0 & 0 & 0 & 0 & 0 & 0 & 0 & 0 \\
\hline 5 & 1 & 0 & 1 & 1 & 2 & 3 & 0 & 1 & 1 \\
\hline 6 & 2 & 0 & 2 & 2 & 3 & 5 & 1 & 1 & 2 \\
\hline 7 & 3 & 0 & 3 & 5 & 2 & 7 & 1 & 1 & 2 \\
\hline 8 & 3 & 2 & 5 & 5 & 3 & 8 & 3 & 0 & 3 \\
\hline 9 & 5 & 2 & 7 & 7 & 4 & 11 & 3 & 1 & 4 \\
\hline 10 & 5 & 3 & 8 & 7 & 5 & 12 & 5 & 1 & 6 \\
\hline 11 & 6 & 4 & 10 & 11 & 5 & 16 & 6 & 2 & 8 \\
\hline 12 & 8 & 3 & 11 & 13 & 6 & 19 & 6 & 4 & 10 \\
\hline
\end{tabular}

Table 2: The German cockroach trap counts in Site A-C during the study period

\begin{tabular}{|c|c|c|c|c|c|c|c|c|c|}
\hline \multirow[b]{2}{*}{$\begin{array}{l}\text { Week (s) } \\
\text { after treatment }\end{array}$} & \multicolumn{3}{|l|}{ Site A } & \multicolumn{3}{|c|}{ Site B } & \multicolumn{3}{|c|}{ Site C } \\
\hline & Adult & Nymph & Total & Adult & Nymph & Total & Adult & Nymph & Total \\
\hline 0 (pre) & 32 & 10 & 42 & 50 & 15 & 65 & 26 & 11 & 37 \\
\hline 1 & 0 & 0 & 0 & 0 & 0 & 0 & 0 & 0 & 0 \\
\hline 2 & 0 & 0 & 0 & 0 & 0 & 0 & 0 & 0 & 0 \\
\hline 3 & 0 & 0 & 0 & 0 & 0 & 0 & 0 & 0 & 0 \\
\hline 4 & 0 & 0 & 0 & 0 & 0 & 0 & 0 & 0 & 0 \\
\hline 5 & 0 & 0 & 0 & 0 & 0 & 0 & 0 & 0 & 0 \\
\hline 6 & 0 & 0 & 0 & 0 & 0 & 0 & 0 & 0 & 0 \\
\hline 7 & 3 & 1 & 4 & 4 & 2 & 6 & 2 & 0 & 2 \\
\hline 8 & 5 & 1 & 6 & 8 & 1 & 9 & 2 & 2 & 4 \\
\hline 9 & 4 & 3 & 7 & 8 & 2 & 10 & 4 & 0 & 4 \\
\hline 10 & 6 & 5 & 11 & 7 & 5 & 12 & 3 & 3 & 6 \\
\hline 11 & 8 & 3 & 13 & 10 & 6 & 16 & 5 & 3 & 8 \\
\hline$\underline{12}$ & 10 & 6 & 16 & 14 & 8 & 22 & 8 & 2 & 10 \\
\hline
\end{tabular}

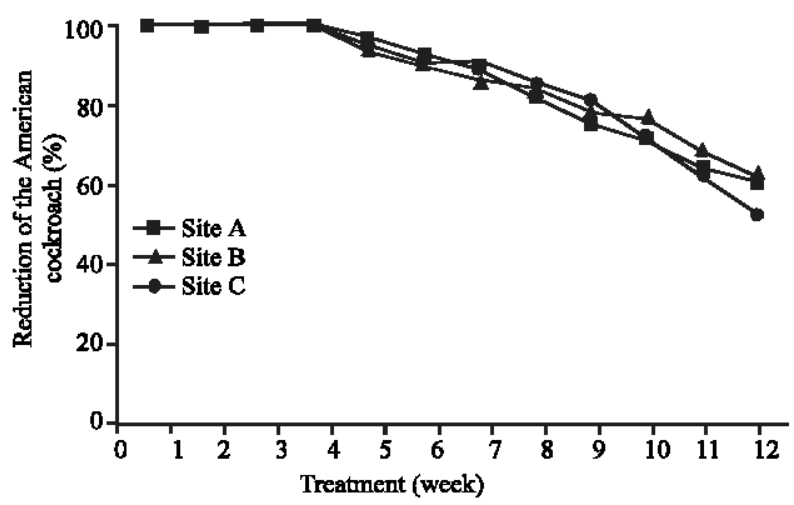

Fig. 1: Hydramethylnon gel bait against Periplaneta americana in three university canteens in Mahasarakham, Thailand

Whereas, the sustained of over $70 \%$ reduction from 7-11 weeks of the post-treatment in site B and from 7-11 weeks of the post-treatment in site A. A minimum reduction of $61.90 \%$ was showed at the 12 th week of the post-treatment in site $\mathrm{A}$. This could be the fact that we were unable to treat the bait in some food preparative areas because of some shops were chaos and have many cracks areas on the wall. However, the gel bait could be

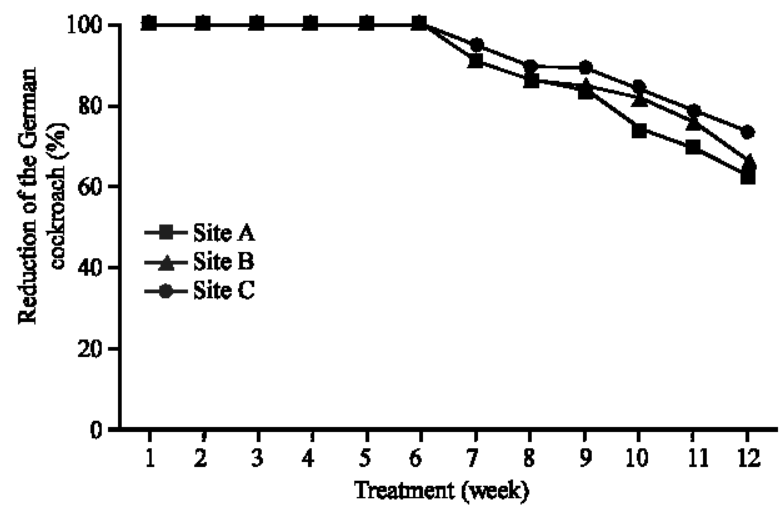

Fig. 2: Hydramethylnon gel bait against Blattella germanica in three university canteens in Mahasarakham, Thailand

cleaned from the wall in the dish wash room. These areas were likely served as the reservoirs for increasing in the number of cockroach trap counts later.

The information obtained from age-class distribution of adult and nymphal stages of the American cockroach after all sites were treated with gel bait. The proportion of nymph to adult at site A-C were increased at 8 weeks of 
the post-treatment, 5 weeks of the post-treatment, respectively. The age-class distributions of adult and nymphal stages of the German cockroach after all sites were treated with gel bait.

In site $\mathrm{A}-\mathrm{C}$, the proportion of nymph to adult increased at 7 weeks of the post-treatment, 7 weeks of the post-treatment, 8 weeks of the post-treatment, respectively. From this results, the new emergence of nymphal stages from oothecae were carried by gravid females which were not affected by the treatment. Gravid females were known to reduce feeding and drinking behaviors during then oviposition period (Cochran, 1983; Sitthicharoenchai et al., 2006). Therefore, the gravid female could not be contact with this toxicant gel baits.

The obtained results were comparable with the report of Lee (1998) which baiting insecticide-resistant to the German cockroaches in food-outlets in Penang, Malaysia using hydramethylnon bait stations.

In this study, there is $>90 \%$ reduction in cockroach trap counts and it was achieved after 4 weeks of the posttreatment and the suppression of cockroach population remained high up to 12 weeks with over $80 \%$ of the reduction.

Relatively, the similar results were reported by Sitthicharoenchai et al. (2006) in which baiting German cockroaches in two university cafeterias in Bangkok, Thailand was also using the hydramethylnon bait. In this study, $>90 \%$ reduction in cockroach trap counts was achieved after 1 week of the post-treatment and the containment of cockroach population remained high up to 12 weeks with over $70 \%$ of the reduction. Moreover, Sulaiman et al. (2007) also reported that hydramethylnon gel bait caused $100 \%$ mortality at 11-14 days on adult laboratory-strain and 14-16 days on field-strain of the American cockroach.

\section{CONCLUSION}

The hydramethylnon gel bait treatment in this study, showed high performance and effective method in controlling both American and German cockroaches in the field, especially in food-outlets, restaurants, kitchens, canteens and markets in Thailand.

\section{ACKNOWLEDGEMENT}

The reaserchers thank Faculty of Public Health, Mahasarakham University for grant support. The researchers wish to thank Mahasarakham University for providing research facilities.

\section{REFERENCES}

Agrawal, V.K. and R. Tilak, 2006. Field performance of imidacloprid gel bait against German cockroaches (Dictyoptera: Blatellidae). Indian J. Med. Res., 124: 89-94.

Benson, E.P. and P.A. Zungoli, 1997. Cockroaches. In: Handbook of Pest Control: The Behavior, Life History and Control of Household Pests, Mallis, A., (Ed.)., 8th Edn., Mallis Handbook and Technical Training Company, Ohio, pp: 123-204.

Brenner, R.J., 1995. Medical and Economic Significance. In: Understanding and Controlling the German Cockroach, Rust, M.K., J.M. Owens and A.D. Reierson, (Eds.). Oxford University Press, New York, pp: 77-92.

Brenner, R.J., K.C. Barnes, R.M. Helm and L.W. Williams, 1991. Modernized society and allergies to arthropods: Risk and challenges to entomologists. Am. Entomol., 37: 143-155.

Cochran, D.G., 1983. Food and water consumption during the reproductive cycle of female German cockroaches. Entomol. Exp. Appl., 34: 51-57.

Gold, R.E., 1995. Alternate Control Strategies. In: Understanding and Controlling the German Cockroach, Rust, M.K., J.M. Owens and A.D. Reierson, (Eds.). Oxford University Press, New York, pp: $325-344$.

James, M.T. and R.F. Harwood, 1969. Herms's Medical Entomology. 6th Edn., MacMillan Publishing, New York, pp: 286.

Kang, B. and J.L. Chang, 1985. Allergenic impact of inhaled arthropod material. Clin. Rev. 3: 363-375.

Lauprasert, P., 2006. Food preference, population dynamics and bacterial harborage of the German cockroach Blattella germanica L. in Bangkok markets. P.Hd. Thesis, Chulalongkorn University, Thailand.

Lee, C.Y., 1997. Insecticide resistance and its underlying mechanisms in the German cockroach, Blattella germanica L. (Dictyoptera: Blattellidae). J. Biosci., 8: 156-172.

Lee, C.Y., 1998. Control of insecticide-resistant German cockroaches, Blattella germanica L. (Dctyoptera: Blattellidae) in food-outlets with hydramethynonbased bait stations. Trop. Biomed., 15: 45-51.

Lee, C.Y., H.H. Yap, N.L. Chong and R.S.T. Lee, 1996. Insecticide resistance and synergism in field collected German cockroaches (Dictyoptera: Blattellidae) in Peninsular Malaysia. Bull. Entomol. Res., 86: 675-682. 
Lee, C.Y., M.S. Khalid, L.C. Lee and N.L. Chong, 2000. Notes on biological parameters of a new domiciliary pest, the smooth cockroach Symploce pallens (Stephens) (Dictyoptera: Blattellidae). Trop. Biomed., 17: 49-52.

Lee, C.Y., N.L. Chong and H.H. Yap, 1993. A study on domiciliary cockroach infestation in Penang, Malaysia. J. Biosci., 4: 95-98.

Lee, L.C. and C.Y. Lee, 2004. Insecticide resistance profiles and possible underlying mechanisms in German cockroaches, Blattella germanica L. (Dictyoptera: Blattellidae) from Peninsular Malaysia. Med. Entomol. Zool., 55: 77-93.

Robinson, W.H., 1988. Roach control with bait stations. Pest Control., 56: 56-60.

Ross, M.H. and E.D. Mullins, 1995. Biology. In: Understanding and Controlling the German Cockroach, Rust, M.K., J.M. Owens and A.D. Reierson, (Eds.). Oxford University Press, New York, pp: $21-48$.

Roth, L.M., 1991. Blattodea, Blattaria (cockroaches). In: The Insects of Australia: A Textbook for Students and Research Workers, Naumann, I.D., (Ed.)., Vol. 1., 2nd Edn., Cornell University Press, New York, pp: 320 .
Sarinho, E., D. Schor, M.A. Veloso and J.A. Rizzo, 2004. There are more asmatics in homes with high cockroach infestation. Braz. J. Med. Biol. Res., 37: 503-510.

Sitthicharoenchai, D., C. Chaisuekul and C.Y. Lee, 2006. Field evaluation of a hydramethylnon gel bait against German cockroaches in Bangkok, Thailand. Med. Entomol. Zool., 57: 361-364.

Sulaiman, S., A.H. Muhammad and H. Othman, 2007. Efficacy of hydramethylnon and fipronil gel baits with laboratory and field strains of Periplaneta Americana (dictyoptera: blattidae) in Malaysia. J. Trop. Med. Parasitol., 30: 64-67.

Tawatsin, A., U. Thavara, J. Chompoosri, W. Kong-ngamsuk, C. Chansang and S. Paosriwong, 2001. Cockroach surveys in 14 provinces of Thailand. J. Vector Ecol., 26: 232-238.

Tsai, C. and H. Lee, 2001. Analysis of specific adaptation to a domicile habitat: A comparative study of two closely related cockroach species. J. Med. Entomol., 38: 245-252.

Wileyto, E.P. and G.M. Boush, 1983. Attraction of the German cockroach, Blattella germanica (Orthoptera: Blatellidae), to some volatile food components. J. Econ. Entomol., 76: 752-756. 